\title{
Hepatitis C in Children and Adolescents: The Good, the Bad, and the Ugly
}

\author{
Naim Alkhouri, MD, and Nizar N. Zein, MD
}

\author{
Corresponding author \\ Nizar N. Zein, MD \\ Department of Gastroenterology and Hepatology, The Cleveland \\ Clinic, 9500 Euclid Avenue, Cleveland, OH 44195, USA. \\ E-mail: zeinn@ccf.org \\ Current Hepatitis Reports 2008, 7:145-151 \\ Current Medicine Group LLC ISSN 1540-3416 \\ Copyright $(0) 2008$ by Current Medicine Group LLC
}

Hepatitis C infection in children is a worldwide health problem with a significant economic burden. Chronic hepatitis $\mathrm{C}$ virus (HCV) infection can progress to cirrhosis and end-stage liver disease during childhood. Most new pediatric cases in the United States and Europe are transmitted vertically from HCV-infected mothers. Antiviral therapy with interferon and ribavirin should be considered in otherwise healthy children to delay disease progression. New diagnostic techniques and antiviral therapies are emerging and may have an impact on our approach to children with HCV infection.

\section{Introduction}

Chronic hepatitis $\mathrm{C}$ virus (HCV) infection is one of the most common liver diseases and a major public health problem. Approximately 4 million Americans are affected [1]; however, chronic liver disease secondary to HCV is less common in children.

The estimated seroprevalence of $\mathrm{HCV}$ antibodies in children in the United States is $0.2 \%$ of those aged 6 to 12 years and $0.4 \%$ of those aged 12 to 19 years [2]. This translates to approximately 240,000 children with antibodies to $\mathrm{HCV}$ and 68,000 to 100,000 who are chronically infected. Earlier studies from Japan suggested a benign natural history and mild histologic disease in children [3], whereas some studies from the United States described a more aggressive course [4]. Pediatric cases presenting with advanced liver disease and cirrhosis requiring liver transplantation have been described $[5 \bullet, 6 \bullet \bullet, 7]$, emphasizing the need for sound strategies to prevent transmission of HCV to children and for better therapeutic options to treat this infection when it occurs.
The Changing Epidemiology of HCV Infection in Children

Before 1991, when routine blood screening for HCV antibodies began, the predominant risk for children acquiring $\mathrm{HCV}$ infection was transfusion of blood or blood products. Transfusion-related HCV has almost disappeared, and vertical transmission currently is by far the most common source of new infections in children in the Western world [8,9]. In the United States, the prevalence of $\mathrm{HCV}$ infection in females of childbearing age is about $1.2 \%$ [1]. The risk of vertical transmission is up to $6 \%$, with a higher risk $(20 \%)$ if the mother is coinfected with HIV [10].

Risk factors for vertical transmission are not well defined. A report from the European Pediatric Hepatitis C Network [11] demonstrated a significant sex effect on the rate of vertical transmission, with newborn girls twice as likely as boys to be infected. The overall rate of vertical transmission was $6.2 \%$, with increased chances of transmission in HCV/HIV-coinfected mothers. The other important findings of this study were that delivery by elective cesarean section had no protective effect on the risk of transmission and that breastfeeding was not associated with transmission.

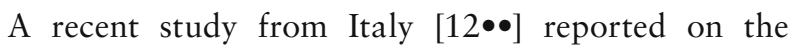
changing epidemiologic profile of 806 children with $\mathrm{HCV}$ infection. The number of children with HCV infection seen between 2000 and 2004 dropped by more than $40 \%$ compared with the previous 5 years, with all new cases attributed to vertical transmission. Factors that may have contributed to reduced vertical transmission include the aging of women who acquired HCV by transfusion, changing drug abuse patterns, antiretroviral therapy in HIV-coinfected mothers, and the efficacy of interferon and ribavirin in treating $\mathrm{HCV}$ infection. The male-to-female ratio for vertically infected children was 0.6 , suggesting that female newborns are more likely than their male counterparts to acquire HCV vertically. This finding was consistent with the previously mentioned European study [11].

HCV has six major genotypes with more than 50 subtypes. In the United States, the most common genotype is $1 \mathrm{a}$, followed by genotypes $1 \mathrm{~b}$ and 2, whereas in Europe, type $1 \mathrm{~b}$ is most prevalent [13]. This genotype distribution 
is changing, with genotypes $1 \mathrm{a}$ and 3 increasing in frequency (more common in injection drug users) compared with genotype $1 \mathrm{~b}$ (more common in transfusion-related transmission) [14]. Data published by Bortolotti et al. [12••] showed that in Italian children, the prevalence of genotypes linked to intravenous drug use ( 3 and 4 ) is increasing whereas genotype $1 \mathrm{~b}$ prevalence is decreasing.

\section{Natural History and Disease Progression}

Data available on the natural history of HCV infection in children are still limited. In a large prospective study of 266 vertically infected children in Europe [15], approximately $20 \%$ of children cleared the infection at a median age of 14.9 months. Decreased clearance likelihood was noted in patients who persistently tested positive on polymerase chain reaction (PCR) assay during the first 12 months of life. Hepatomegaly was noted in $10 \%$ of chronically infected patients, although most children were asymptomatic.

It appears that the natural history in patients whose infection was acquired via transfusion depends on their underlying disease, with higher rates of HCV clearance in patients transfused during surgery for congenital heart disease [16] compared with those transfused for malignancy. Disease progression could be affected by the comorbid illness. In one study in children who acquired HCV during treatment for cancer [17], one patient died from liver failure and two others died from hepatocellular carcinoma (HCC), suggesting a more aggressive HCV infection in this population.

Several factors may affect disease progression in adults, including older age at infection onset, duration of infection, male sex, race, alcohol consumption, smoking, daily cannabis use, insulin resistance and metabolic syndrome, iron overload, and coinfection with hepatitis B virus (HBV), HIV, or Schistosoma [18]. Recent studies suggest an important role for host genetic polymorphisms and viral factors. Polymorphisms of TGF- $\beta 1$ and angiotensin II have been linked to hepatic fibrosis in chronic hepatitis C $[19,20]$. Also, the core protein of HCV has been shown to promote oxidative stress and apoptosis, which may induce fibrosis [21,22].

Less is known about disease progression in children; however, it appears that transfusion-related infection, older age at acquisition of $\mathrm{HCV}$, and longer duration are all associated with more aggressive disease. New studies in adults have suggested that daily cannabis smoking is a risk factor for fibrosis progression [23]. Cannabinoid receptors $\mathrm{CB} 1$ and $\mathrm{CB} 2$ are upregulated in chronic liver disease, and the activation of CB1 receptor is profibrogenic $[24,25]$. A new prospective cohort study by Ishida et al. [26•] showed that the odds of daily cannabis users developing moderate to severe fibrosis are seven times greater than those of non-daily users. This finding may have similar implications for adolescent patients who have chronic HCV and smoke marijuana.

\section{Histopathologic Spectrum and Liver Biopsy Findings}

The characteristic histologic features on liver biopsy are similar in adults and children and include variable degrees of necroinflammation and fibrosis, steatosis, portal lymphoid aggregates, and, occasionally, bile duct damage [27]. In general, necroinflammation is mild in children. The degree of fibrosis has varied considerably among different studies, ranging from $4 \%$ in the study by Kage et al. [3] to $44 \%$ in the study by Badizadegan et al. [4].

In a retrospective review of liver biopsies from $60 \mathrm{HCV}-$ infected children, bridging fibrosis was noted in $12 \%$ [ $28 \bullet]$. In another series of 112 patients from Spain and Italy, Guido et al. [29] reported bridging fibrosis in $26 \%$, and the degree of fibrosis correlated with age and duration of infection. Recently, the Peds-C trial (a treatment trial for HCV in children) provided a great opportunity to report on liver biopsies from 121 children with chronic HCV [30••]. Only $4.2 \%$ had bridging fibrosis, and this lower rate may have been related to the fact that other studies contained a large proportion of children with transfusion-related infection. Necroinflammation was mild, with minimal inflammation in $42 \%$ of children. A noteworthy finding of this study was that overweight children had more fibrosis.

\section{Steatosis in children with HCV: viral or metabolic}

Insulin resistance has been implicated in steatosis development and fibrosis progression in adults with chronic HCV [31]. It is believed that steatosis associated with HCV genotype 1 is a marker of metabolic abnormalities such as diabetes, obesity, and the metabolic syndrome and has been termed metabolic fat. On the other hand, steatosis in HCV genotype 3 is related to the virus itself and has been termed viral fat [32].

Several recent studies reported that steatosis is also common in children with chronic HCV. Guido et al. [33••] reported steatosis in $27 \%$ of 66 children with chronic $\mathrm{HCV}$, mostly of genotype 1 . A strong association was seen between steatosis and body mass index (BMI) and triglyceride levels, demonstrating that metabolic abnormalities affect the degree of steatosis in HCV genotype 1 infection. A new report by Giannattasio et al. [34••] showed steatosis in $25 \%$ of pediatric patients. More importantly, BMI did not differ significantly between children with steatosis and those without it, despite the fact that most of these children had HCV genotype 1, revealing a possible direct association between genotypes other than genotype 3 and hepatic steatosis in children. Finally, liver biopsies from the Peds-C trial showed steatosis in $42 \%$ of the patients, indicating that there may be geographic trends, with more steatosis in the United States $[30 \bullet \bullet]$.

\section{Diagnosis of Vertically Transmitted HCV}

Maternal IgG antibodies to HCV can passively cross the placenta. It may take the infant more than 12 months to clear 
these antibodies [35], making the diagnosis of vertically transmitted HCV particularly difficult. HCV RNA testing with PCR is used to make the diagnosis earlier in life; however, PCR testing has its limitations, including false-positive results due to contamination by maternal blood.

According to Roberts and Yeung [10], infants born to antibody to HCV (anti-HCV)-positive mothers are considered HCV infected if they have positive PCR for HCV RNA in at least two serum samples during the first year of life and/or if they are anti-HCV positive after 18 to 24 months of life. The National Institutes of Health issued a consensus statement in 2002 recommending that these infants undergo PCR testing on two occasions between the ages of 2 and 6 months and/or anti-HCV antibody testing after 15 months. A European study demonstrated that 31\% of infected infants screened had detectable HCV RNA as early as 3 days of age, suggesting intrauterine infection. However, in most patients the HCV RNA reaches detectable levels only after a few weeks, which is more consistent with perinatal rather than intrauterine transmission.

A study from the European Pediatric Hepatitis C Network [36 $]$ addressed the accuracy of HCV RNA PCR tests in the early diagnosis of vertically transmitted HCV. The gold standard to confirm the presence of HCV infection was seropositivity for anti-HCV at or beyond 18 months. PCR testing at birth had a low sensitivity $(22 \%)$, which increased to $90 \%$ at 1 month of age and thereafter. According to the authors, the first HCV RNA test should be done after the first month of life and if negative should be confirmed with a negative anti-HCV antibody test at the age of 9 to 15 months (because negative PCR rarely may be observed in infected children with fluctuating viremia).

\section{Management of Chronic Hepatitis C in Children Counseling and lifestyle modification}

HCV-infected children and their families need to be counseled regarding prevention of viral transmission. Sharing toothbrushes, razors, and nail clippers should be avoided; teenagers with multiple sexual partners should use condoms to prevent sexual transmission [37]. These children should receive the hepatitis $A$ and hepatitis $B$ vaccines to prevent further damage to their liver in case of exposure to these viruses [38]. Alcohol use and smoking should be strongly discouraged, and according to new evidence, teenagers should abstain from marijuana use. A wellbalanced, healthy diet should be encouraged to prevent obesity and insulin resistance, which may be associated with accelerated fibrosis and treatment failure. For obese adolescents, weight loss should be recommended.

A new report from Australia addresses the issue of health-related quality of life for children who acquire HCV before the age of 12 months and for their parents [39•]. Physical and psychosocial summary scores were significantly lower in children with HCV than in those without it. Furthermore, $73 \%$ of parents were particularly concerned about the future health of their child, with $20 \%$ finding the possibility of cirrhosis or liver cancer "hard to bear." These data emphasize the need for medical and social support services for families of children with chronic hepatitis C.

\section{Antiviral therapy}

Selecting children with chronic hepatitis C for antiviral therapy may be challenging given the incomplete understanding of the natural history of HCV infection in children and the side effects associated with treatment. Earlier studies with interferon (IFN) monotherapy suggested a significantly higher sustained virologic response (SVR) in children compared with adults $(36 \%$ vs $8 \%$, respectively) [40]. In a large study by the International Pediatric Hepatitis C Therapy Group [41••], adding ribavirin resulted in a better SVR rate in children $(46 \%)$ compared with that achieved with IFN monotherapy $(36 \%)$. SVR was significantly higher in patients with HCV genotypes 2 and $3(84 \%)$ than in those with HCV genotype $1(36 \%)$. When the patients were categorized as children (5-12 years old) and adolescents ( $>12$ years old), SVR rates differed significantly $(57 \%$ vs $26 \%$, respectively), suggesting that treatment early in life may be more beneficial. The most common adverse event observed was influenza-like syndrome, and the most common severe adverse event was neutropenia. One unique side effect of IFN therapy in the pediatric population is its association with decreased linear growth and weight; however, in the International Pediatric Hepatitis C Therapy trial, compensatory increases were noted in height and weight after treatment discontinued. These studies led to the approval of IFN- $\alpha-2 b$ and ribavirin in the United States for patients between 3 and 18 years of age with chronic hepatitis C.

The introduction of peginterferon (PEG-IFN) in adults has improved response rates by $10 \%[42,43]$, and PEG-IFN is an attractive option in children because of its weekly dosing. Three studies reported on the use of PEG-IFN in children. The first, using PEG-IFN- $\alpha-2 a$ monotherapy in 14 children with chronic HCV infection, showed an acceptable safety profile and an SVR rate of $43 \%$ [44•]. Another small study evaluated PEG-IFN- $\alpha-$ $2 \mathrm{~b}$ combined with ribavirin in 10 pediatric patients [45]. Thirty percent of the patients achieved an SVR, and no serious side effects were reported. The largest published study to date on PEG-IFN- $\alpha-2 b$ and ribavirin combination therapy in children included 62 patients (ages 2-17 years) $[46 \bullet \bullet$. SVR was achieved in $48 \%$ of patients with genotype 1 and in $100 \%$ of patients with genotypes 2 and 3. Leukopenia was noted in $83 \%$; however, only three patients required dose reduction. Other side effects included the development of thyroid antibodies and thyroid dysfunction in $10 \%$, flulike symptoms in $82 \%$, and diabetes mellitus type 1 in one patient. A summary of these studies is provided in Table 1. 


\begin{tabular}{|c|c|c|c|c|c|}
\hline Study & Year & Study type & Patients, $n$ & Treatment & SVR rate, $\%$ \\
\hline Jacobson et al. [40] & 2002 & Meta-analysis of 19 trials & 366 & IFN- $\alpha$ monotherapy & 36 \\
\hline $\begin{array}{l}\text { Gonzalez-Peralta } \\
\text { et al. }[41 \bullet \bullet]\end{array}$ & 2005 & Large multicenter & 118 & $\begin{array}{l}\text { IFN- } \alpha-2 b+ \\
\text { ribavirin }\end{array}$ & 46 \\
\hline \multirow[t]{2}{*}{ Wirth et al. $[46 \bullet \bullet]$} & 2005 & Open-label pilot & 62 & $\begin{array}{l}\text { PEG-IFN- } \alpha-2 b+ \\
\text { ribavirin }\end{array}$ & 48 for HCV 1 \\
\hline & & & & & 100 for HCV 2 or 3 \\
\hline Schwarz et al. $[44 \bullet]$ & 2006 & $\begin{array}{l}\text { Small open-label } \\
\text { multicenter }\end{array}$ & 14 & $\begin{array}{l}\text { PEG-IFN- } \alpha-2 a \\
\text { monotherapy }\end{array}$ & 43 \\
\hline Baker et al. [45] & 2007 & $\begin{array}{l}\text { Small open-label } \\
\text { single-center }\end{array}$ & 10 & $\begin{array}{l}\text { PEG-IFN- } \alpha-2 b+ \\
\text { ribavirin }\end{array}$ & 30 \\
\hline
\end{tabular}

The results of a large multicenter US and European study (the Peds- $\mathrm{C}$ trial) are anticipated to provide greater insights into the safety and efficacy of PEG-IFN and ribavirin in children with chronic HCV infection.

The general consensus is that liver biopsy is not warranted before antiviral therapy in patients with genotypes 2 and 3 because of the higher SVR rate achieved with treatment. Performing a liver biopsy before initiating therapy in patients with genotype 1 is controversial. Schwarz et al. [47] recently reported on a new protocol for safely performing percutaneous liver biopsies in children with hemophilia. The authors described 20 liver biopsies in patients with factor VIII deficiency, with no major complications.

\section{Liver transplantation for pediatric chronic HCV infection}

Outcomes of liver transplantation for HCV in adults are characterized by almost universal viremia; worse outcomes, with decreased patient and allograft survival; and accelerated disease progression $[48,49]$. Nevertheless, chronic HCV infection is still the most common indication for liver transplantation in adults in the United States.

Orthotopic liver transplantation (OLT) remains the only available treatment option for children with endstage liver disease secondary to HCV, although fewer data are available in the pediatric literature. Udell et al. [7] reported the clinical recurrence of HCV 3 years after transplantation in a pediatric patient who acquired the infection vertically. A large study on the natural history of HCV in children after OLT revealed patient and allograft survival rates of $71.6 \%$ and $55 \%$, respectively, at 5 years [ $5 \bullet$. These rates were lower after retransplantation $(55 \%$ for patient survival and $33.8 \%$ for allograft survival). Most retransplantations were done for HCV recurrence, with a mean of 1.2 transplants per patient for HCV. The 5-year survival rate of $55 \%$ following retransplantation for HCV argues strongly for retransplantation for children with end-stage liver disease due to recurrent $\mathrm{HCV}$.

\section{Future Directions and Research Demands}

Although HCV infection in childhood tends to progress more slowly, the dramatic increase in childhood obesity may have a major impact on the natural history, with accelerated disease progression and decreased response to antiviral therapy. A small study in adults showed that weight loss and physical activity in overweight patients with chronic hepatitis $\mathrm{C}$ may lead to a decrease in insulin resistance and alanine aminotransferase, emphasizing the importance of a healthy lifestyle in these patients [50]. Specific pediatric studies are needed to assess the effects of obesity on HCV progression.

Liver biopsy is still considered the gold standard for assessing disease activity; however, it is an invasive test with potential for serious complications. Our group recently developed a simple noninvasive scoring system to identify the subgroup of patients with chronic HCV who would derive the most benefit from liver biopsy [51]. Three simple laboratory variables were used (platelet count, serum aspartate aminotransferase level, and serum albumin level), with a total score ranging between 0 and 9 points. A cutoff point of 4 had $99 \%$ specificity and $94 \%$ positive predictive value in predicting severe liver fibrosis (stages III and IV). Other studies have described different scores for predicting liver fibrosis in patients with chronic HCV without the need for liver biopsy [52,53].

Ongoing research is focusing on noninvasive, reliable tests to monitor disease progression. Bantel et al. [54] described the use of a serum apoptosis biomarker, cytokeratin 18, to detect liver fibrosis in patients with chronic HCV and normal aminotransferases. Wieckowska et al. [55] used the same biomarker to assess disease severity in patients with nonalcoholic fatty liver disease and found that cytokeratin 18 levels were markedly increased in patients with nonalcoholic steatohepatitis compared with patients with simple steatosis or normal biopsies. Recently, Elgouhari et al. [56] further validated the value of cytokeratin 18 level for assessing hepatic fibrosis in a large cohort of patients $(\mathrm{N}=215)$ with nonalcoholic fatty liver disease and chronic viral hepatitis (HCV and HBV). 
Novel imaging modalities to assess liver fibrosis have been developed using elastography, which is based on the concept that the liver becomes less elastic when more fibrosis is present. Two promising new techniques are magnetic resonance elastography and transient elastography using an ultrasound probe [57].

Given the magnitude of the HCV epidemic and the complications associated with HCV-induced end-stage liver disease, a breakthrough in managing HCV infection is needed. Currently, several protease inhibitors and polymerase inhibitors are being investigated for treating chronic hepatitis $\mathrm{C}$ in adults [58]. Telaprevir is a specific reversible inhibitor of the HCV genotype 1 serine protease, which is essential for HCV replication. Several reports demonstrated its potent antiviral effects, and its efficacy is enhanced when it is combined with PEG-IFN $[59,60]$. Boceprevir is another protease inhibitor under development that has shown promising early results [61]. Both these proteases are entering phase 3 evaluation and may be available within the next few years. Studies in children have yet to be performed. Other novel therapies are in early stages of development or, in some cases, have already been abandoned, including ribozymes, small interfering RNAs, antisense molecules, and viral entry inhibitors [62]. The role of these new therapies in $\mathrm{HCV}$-infected children remains to be determined by future studies.

\section{Conclusions}

Hepatitis $\mathrm{C}$ in children has multiple unique aspects that may be good, bad, or ugly. The good is that the prevalence in children is low and the number of new cases is decreasing as the result of screening of blood and blood products. In addition, new therapies are emerging and may improve outcomes. The bad is related to the progressive natural history of HCV infection and the suboptimal efficacy of the available treatments for children. The ugly lies in the fact that chronic HCV infection leads to increased liver-related mortality in infected adults and children. It also significantly increases the demand for liver transplantation in this population. New research and clinical trials in pediatric HCV infection are of paramount importance and should receive adequate support.

\section{Disclosures}

Dr. Zein has received research support from Roche, Schering-Plough, Vertex, and Centocor. No other potential conflicts of interest relevant to this article were reported.

\section{References and Recommended Reading}

Papers of particular interest, published recently, have been highlighted as:

- Of importance

$\bullet \quad$ Of major importance

1. Alter MJ, Kruszon-Moran D, Nainan OV, et al.: The prevalence of hepatitis $\mathrm{C}$ virus infection in the United States, 1988 through 1994. N Engl J Med 1999, 41:556-562.

2. Hepatitis $\mathrm{C}$ virus infection. American Academy of Pediatrics. Committee on Infectious Diseases. Pediatrics 1998, 101:481-485.

3. Kage M, Fujisawa T, Shiraki K, et al.: Pathology of chronic hepatitis C in children. Child Liver Study Group of Japan. Hepatology 1997, 26:771-775.

4. Badizadegan K, Jonas MM, Ott MJ, et al.: Histopathology of the liver in children with chronic hepatitis $\mathrm{C}$ viral infection. Hepatology 1998, 28:1416-1423.

5.- Barshes NR, Udell IW, Lee TC, et al.: The natural history of hepatitis $\mathrm{C}$ virus in pediatric liver transplant recipients. Liver Transpl 2006, 12:1119-1123.

This is an excellent review of pediatric patients with HCV infection who underwent liver transplantation between 1998 and 2005. It demonstrates the high risk for $\mathrm{HCV}$ recurrence, which may require retransplantation.

6.• Rumbo C, Fawaz RL, Emre SH, et al.: Hepatitis C in children: a quaternary referral center perspective. J Pediatr Gastroenterol Nutr 2006, 43:209-216.

This is a review of all pediatric patients seen in a tertiary care center between 1999 and 2004. It shows that HCV infection in children is a progressive disease and that posttransplantation recurrence is almost universal.

7. Udell IW, Barshes NR, Finegold MJ, et al.: Hepatitis C viral recurrence in a pediatric patient following liver transplantation. Pediatr Transplant 2006, 10:617-622.

8. Bortolotti F, Resti M, Giacchino R, et al.: Changing epidemiologic pattern of chronic hepatitis $\mathrm{C}$ virus infection in Italian children. J Pediatr 1998, 133:378-381.

9. Jonas MM: Children with hepatitis C. Hepatology 2002, 36:S173-S178.

10. Roberts EA, Yeung L: Maternal-infant transmission of hepatitis C virus infection. Hepatology 2002, 36:S106-S113.

11. A significant sex-but not elective cesarean section-effect on mother-to-child transmission of hepatitis $\mathrm{C}$ virus infection. J Infect Dis 2005, 192:1872-1879.

12.• Bortolotti F, Iorio R, Resti M, et al.: Epidemiological profile of 806 Italian children with hepatitis $\mathrm{C}$ virus infection over a 15-year period. J Hepatol 2007, 46:783-790.

This large epidemiologic study in children with HCV revealed that the prevalence of HCV infection in children is decreasing, with almost all new cases acquired via vertical transmission.

13. Pawlotsky JM: Hepatitis $C$ virus genetic variability: pathogenic and clinical implications. Clin Liver Dis 2003, 7:45-66.

14. Wasley A, Alter MJ: Epidemiology of hepatitis C: geographic differences and temporal trends. Semin Liver Dis 2000, 20:1-16.

15. Three broad modalities in the natural history of vertically acquired hepatitis $\mathrm{C}$ virus infection. Clin Infect Dis 2005, 41:45-51.

16. Vogt M, Lang T, Frosner G, et al.: Prevalence and clinical outcome of hepatitis $\mathrm{C}$ infection in children who underwent cardiac surgery before the implementation of blood-donor screening. N Engl J Med 1999, 341:866-870.

17. Strickland DK, Riely CA, Patrick CC, et al.: Hepatitis C infection among survivors of childhood cancer. Blood 2000, 95:3065-3070. 
18. Missiha SB, Ostrowski M, Heathcote EJ: Disease progression in chronic hepatitis C: modifiable and nonmodifiable factors. Gastroenterology 2008, 134:1699-1714.

19. Kanzler S, Baumann M, Schirmacher P, et al.: Prediction of progressive liver fibrosis in hepatitis $\mathrm{C}$ infection by serum and tissue levels of transforming growth factor-beta. J Viral Hepat 2001, 8:430-437.

20. Powell EE, Edwards-Smith CJ, Hay JL, et al.: Host genetic factors influence disease progression in chronic hepatitis $\mathrm{C}$. Hepatology 2000, 31:828-833.

21. Chou AH, Tsai HF, Wu YY, et al.: Hepatitis C virus core protein modulates TRAIL-mediated apoptosis by enhancing Bid cleavage and activation of mitochondria apoptosis signaling pathway. J Immunol 2005, 174:2160-2166.

22. Okuda M, Li K, Beard MR, et al.: Mitochondrial injury, oxidative stress, and antioxidant gene expression are induced by hepatitis $\mathrm{C}$ virus core protein. Gastroenterology 2002, 122:366-375.

23. Hezode C, Roudot-Thoraval F, Nguyen S, et al.: Daily cannabis smoking as a risk factor for progression of fibrosis in chronic hepatitis C. Hepatology 2005, 42:63-71.

24. Julien B, Grenard P, Teixeira-Clerc F, et al.: Antifibrogenic role of the cannabinoid receptor CB2 in the liver. Gastroenterology 2005, 128:742-755.

25. Teixeira-Clerc F, Julien B, Grenard P, et al.: CB1 cannabinoid receptor antagonism: a new strategy for the treatment of liver fibrosis. Nat Med 2006, 12:671-676.

26. Ishida JH, Peters MG, Jin C, et al.: Influence of cannabis use on severity of hepatitis C disease. Clin Gastroenterol Hepatol 2008, 6:69-75.

This new prospective study showed that daily cannabis use is strongly associated with moderate to severe fibrosis in patients with chronic HCV infection. It supports a role for cannabinoid receptors in the progression of liver fibrosis.

27. Goodman ZD, Ishak KG: Histopathology of hepatitis C virus infection. Semin Liver Dis 1995; 15:70-81.

28. Mohan P, Colvin C, Glymph C, et al.: Clinical spectrum and histopathologic features of chronic hepatitis $\mathrm{C}$ infection in children. J Pediatr 2007, 150:168-174, 174e1.

A carefully conducted histopathologic study in children with HCV infection that has enriched our knowledge of the natural history of pediatric HCV.

29. Guido M, Bortolotti F, Leandro G, et al.: Fibrosis in chronic hepatitis $C$ acquired in infancy: is it only a matter of time? Am J Gastroenterol 2003, 98:660-663.

30.• Goodman ZD, Makhlouf HR, Liu L, et al.: Pathology of chronic hepatitis $\mathrm{C}$ in children: liver biopsy findings in the Peds-C Trial. Hepatology 2008, 47:836-843.

This is one of the largest studies on the histopathology of chronic hepatitis $\mathrm{C}$ in children. It demonstrated that inflammation, fibrosis, and steatosis were milder in children than in their adult counterparts. It also showed that overweight children had more fibrosis.

31. Zein NN, Poterucha JJ: Steatosis in hepatitis C: the missing link to metabolic abnormalities? Am J Gastroenterol 2006, 101:2616-2618.

32. Hanouneh IA, Feldstein AE, Lopez R, et al.: Clinical significance of metabolic syndrome in the setting of chronic hepatitis C virus infection. Clin Gastroenterol Hepatol 2008, 6:584-589.

33.• Guido M, Bortolotti F, Jara P, et al.: Liver steatosis in children with chronic hepatitis C. Am J Gastroenterol 2006, 101:2611-2615.

A retrospective report on the frequency and clinical significance of steatosis in pediatric HCV and its relationship to metabolic abnormalities.

34.• Giannattasio A, Spagnuolo MI, Sepe A, et al.: Is HCV infection associated with liver steatosis also in children? J Hepatol 2006, 45:350-354.

This retrospective study suggested that steatosis in children with HCV infection may be related to HCV genotype 1 itself rather than metabolic abnormalities in the host.
35. Giacchino R, Tasso L, Timitilli A, et al.: Vertical transmission of hepatitis $C$ virus infection: usefulness of viremia detection in HIV-seronegative hepatitis $\mathrm{C}$ virus-seropositive mothers. J Pediatr 1998, 132:167-169.

36. Polywka S, Pembrey L, Tovo PA, Newell ML: Accuracy of HCV-RNA PCR tests for diagnosis or exclusion of vertically acquired HCV infection. J Med Virol 2006, 78:305-310.

This study addressed the use of HCV RNA PCR testing to diagnose vertically acquired HCV. It suggested delaying the first PCR testing until after the first month of life to increase its sensitivity.

37. Strader DB, Wright T, Thomas DL, Seeff LB: Diagnosis, management, and treatment of hepatitis C. Hepatology 2004, 39:1147-1171.

38. Delgado-Borrego A, Jonas MM: Treatment options for hepatitis C infection in children. Curr Treat Options Gastroenterol 2004, 7:373-379.

39. Nydegger A, Srivastava A, Wake M, et al.: Health-related quality of life in children with hepatitis $\mathrm{C}$ acquired in the first year of life. J Gastroenterol Hepatol 2008 , 23:226-230.

This is one of the few studies addressing the issue of quality of life in children with chronic HCV infection. It showed that this chronic infection can affect the mental and physical well-being of these children and their parents.

40. Jacobson KR, Murray K, Zellos A, Schwarz KB: An analysis of published trials of interferon monotherapy in children with chronic hepatitis C. J Pediatr Gastroenterol Nutr 2002, 34:52-58.

41.• Gonzalez-Peralta RP, Kelly DA, Haber B, et al.: Interferon alfa-2b in combination with ribavirin for the treatment of chronic hepatitis $\mathrm{C}$ in children: efficacy, safety, and pharmacokinetics. Hepatology 2005, 42:1010-1018.

This large multicenter trial demonstrated an acceptable safety profile and efficacy for IFN- $\alpha$ and ribavirin combination therapy in children with chronic HCV.

42. Fried MW, Shiffman ML, Reddy KR, et al.: Peginterferon alfa-2a plus ribavirin for chronic hepatitis $\mathrm{C}$ virus infection. N Engl J Med 2002, 347:975-982.

43. Manns MP, McHutchison JG, Gordon SC, et al.: Peginterferon alfa-2b plus ribavirin compared with interferon alfa-2b plus ribavirin for initial treatment of chronic hepatitis C: a randomised trial. Lancet 2001, 358:958-965.

44. Schwarz KB, Mohan P, Narkewicz MR, et al.: Safety, efficacy and pharmacokinetics of peginterferon alpha2a $(40 \mathrm{kd})$ in children with chronic hepatitis C. J Pediatr Gastroenterol Nutr 2006, 43:499-505.

This small open-label trial assessed the safety and efficacy of PEG-IFN monotherapy in pediatric HCV infection.

45. Baker RD, Dee D, Baker SS: Response to pegylated interferon alpha-2b and ribavirin in children with chronic hepatitis C. J Clin Gastroenterol 2007, 41:111-114.

46.• Wirth S, Pieper-Boustani H, Lang T, et al.: Peginterferon alfa-2b plus ribavirin treatment in children and adolescents with chronic hepatitis C. Hepatology 2005, 41:1013-1018. This is the largest study to date on PEG-IFN and ribavirin combination therapy in HCV-infected children. It demonstrated an acceptable SVR rate in patients with HCV genotype 1 and an excellent response rate in patients with HCV genotypes 2 and 3.

47. Schwarz KB, Zellos A, Stamato L, et al.: Percutaneous liver biopsy in hemophiliac children with chronic hepatitis C virus infection. J Pediatr Gastroenterol Nutr 2008, 46:423-428.

48. Berenguer M: Recurrent hepatitis C: worse outcomes established, interventions still inadequate. Liver Transpl 2007, 13:641-643.

49. Berenguer $M$, Prieto $M$, Palau A, et al.: Severe recurrent hepatitis $\mathrm{C}$ after liver retransplantation for hepatitis C virus-related graft cirrhosis. Liver Transpl 2003, 9:228-235. 
50. Hickman IJ, Jonsson JR, Prins JB, et al.: Modest weight loss and physical activity in overweight patients with chronic liver disease results in sustained improvements in alanine aminotransferase, fasting insulin, and quality of life. Gut 2004, 53:413-419.

51. Metwally MA, Zein CO, Zein NN: Predictors and noninvasive identification of severe liver fibrosis in patients with chronic hepatitis C. Dig Dis Sci 2007, 52:582-588.

52. Bonacini M, Hadi G, Govindarajan S, Lindsay KL: Utility of a discriminant score for diagnosing advanced fibrosis or cirrhosis in patients with chronic hepatitis $\mathrm{C}$ virus infection. Am J Gastroenterol 1997, 92:1302-1304.

53. Imbert-Bismut F, Ratziu V, Pieroni L, et al.: Biochemical markers of liver fibrosis in patients with hepatitis $C$ virus infection: a prospective study. Lancet 2001, 357:1069-1075.

54. Bantel H, Lugering A, Heidemann J, et al.: Detection of apoptotic caspase activation in sera from patients with chronic HCV infection is associated with fibrotic liver injury. Hepatology 2004, 40:1078-1087.

55. Wieckowska A, Zein NN, Yerian LM, et al.: In vivo assessment of liver cell apoptosis as a novel biomarker of disease severity in nonalcoholic fatty liver disease. Hepatology 2006, 44:27-33.

56. Elgouhari H, Zein N, Elsayed A, et al.: Caspase activity mirrored by plasma cytokeratin-18 fragments' level predicts advanced hepatic fibrosis related to non alcoholic fatty liver disease and chronic viral hepatitis [abstract 278]. Presented at Digestive Disease Week 2008. San Diego, CA; May 17-22, 2008.
57. Manning DS, Afdhal NH: Diagnosis and quantitation of fibrosis. Gastroenterology 2008, 134:1670-1681.

58. Modi AA, Hoofnagle JH: New therapies for hepatitis C. Hepatology 2007, 46:615-617.

59. Forestier N, Reesink HW, Weegink CJ, et al.: Antiviral activity of telaprevir (VX-950) and peginterferon alfa-2a in patients with hepatitis C. Hepatology 2007, 46:640-648.

60. Reesink HW, Zeuzem S, Weegink CJ, et al.: Rapid decline of viral RNA in hepatitis $\mathrm{C}$ patients treated with VX950: a phase Ib, placebo-controlled, randomized study. Gastroenterology 2006, 131:997-1002.

61. Sarrazin C, Rouzier R, Wagner F, et al.: SCH 503034, a novel hepatitis $\mathrm{C}$ virus protease inhibitor, plus pegylated interferon alpha-2b for genotype 1 nonresponders. Gastroenterology 2007, 132:1270-1278.

62. McHutchison JG, Bartenschlager R, Patel K, Pawlotsky JM: The face of future hepatitis $\mathrm{C}$ antiviral drug development: recent biological and virologic advances and their translation to drug development and clinical practice. J Hepatol 2006, 44:411-421. 